\title{
Removal of Methylene Blue from Aqueous Effluent Using Fixed Bed of Groundnut Shell Powder
}

\author{
Sunil Kumar, V. Gunasekar, and V. Ponnusami \\ Department of Chemical Engineering, School of Chemical and Biotechnology, SASTRA University, \\ Thirumalaisamudram 613 401, Tamil Nadu, Thanjavur, India
}

Correspondence should be addressed to V. Ponnusami; vponnu@chem.sastra.edu

Received 27 January 2012; Revised 27 April 2012; Accepted 17 May 2012

Academic Editor: Subrata Mondal

Copyright (c) 2013 Sunil Kumar et al. This is an open access article distributed under the Creative Commons Attribution License, which permits unrestricted use, distribution, and reproduction in any medium, provided the original work is properly cited.

Removal of methylene blue from aqueous solution using a low-cost adsorbent groundnut shell powder (GNSP) was studied using fixed bed. Bed service depth model and Thomas model were employed to study the adsorption kinetics and to predict break-through curves for the system. Both models fit the experimental data very well with very high $R^{2}$ values. Percentage color removal increased with increase in bed height. It was found that adsorption potential of GNSP was in the range of 0.238 to $0.272 \mathrm{~kg} / \mathrm{kg}$ of adsorbent. These results show that the GNSP can be effectively used as low-cost alternate adsorbent for the removal of pollutants from aqueous streams.

\section{Introduction}

Dyes are widely used by several industries like plastics, textile, and paper, to color their final products [1]. Presence of dyes in industrial effluent poses serious threat to the environment. It interferes with the normal photosynthetic activities of aquatic life [2-4]. Majority of dyes are recalcitrant and usually take very long time for biodegradation. Moreover, it is reported that the intermediates formed during biodegradation of the dyes are more toxic than the original molecules. Photochemical oxidation can mineralize the compounds efficiently, but it is energy intensive and therefore not preferred for largescale applications. Similarly, many other physicochemical techniques available for color removal are either costly or inefficient. Among them adsorption is proven to be one of the most efficient techniques $[5,6]$. However, as cost of conventional adsorbents is too high, it is necessary to search for low cost adsorbents. Scientists are now exploring the possibilities of using low-cost agro wastes as alternate adsorbents. Agro wastes like rice husk [7-9], wheat husk $[10,11]$, saw dust of various trees [12-14], peels of fruits [15], seeds [16, 17], and leaves of various plants [18-22] have been studied recently. In this work, groundnut shell powder (GNSP) is used for the adsorption of methylene blue from aqueous effluent.
Groundnut shell is a byproduct of groundnut oil industry. It is a solid waste to be disposed off properly. If this material could be effectively used as an alternate adsorbent, then it can have double-fold advantage. In order to assess the adsorption potential of the GNSP, equilibrium studies were performed in batch mode. However, continuous adsorption is preferred over batch adsorption for large-scale applications owing to higher efficiency and effective utilisation of adsorbent capacity. Therefore, in this work fixed bed packed with GNSP was employed for adsorption of methylene blue from aqueous solution.

\section{Materials and Methods}

2.1. Adsorbate. Methylene blue (MB, chemical formula: C16H18N3SCl; FW: $320 \mathrm{~g} \mathrm{~mol}^{-1}, \lambda_{\max }=662 \mathrm{~nm}$, class: thiazine, CI classification number: 52015) was obtained from the Ranbaxy Laboratories Limited (India) and used without further purification. $\mathrm{MB}$ is not regarded as acutely toxic, but it can have various harmful effects. On inhalation, it can give rise to short periods of rapid or difficult breathing, while by ingestion through the mouth it produces a burning sensation and may cause nausea, vomiting, diarrhea, and gastritis [23, 24]. Stock solutions were prepared as described in Ponnusami et al. [19]. Frequently in adsorption studies, 
MB is used as model dye for two reasons [18]: (i) MB is one of the commonly used commercial dye and (ii) MB is well known for its adsorption characteristics.

2.2. Adsorbent. The groundnut shell was first washed thoroughly with unpurified water to remove adhering foreign particles from the surface and then dried in solar light. Then it was dried in hot-air oven at $70^{\circ} \mathrm{C}$ for about $24 \mathrm{~h}$. After drying, the adsorbent was crushed in ball mill and then size separated using sieve shaker. Particles of size BSS \#-60+72 were collected and then stored in a plastic container for further use. Physical characteristics of the GNSP were determined, and results are summarized in Table 1. $\mathrm{pH}$ zero point charge $\left(\mathrm{pH}_{\mathrm{zpc}}\right)$ of the adsorbent was determined by powder addition method [25].

Infrared spectrum of the sample was obtained using PerkinElmer spectrum RX I model Fourier transform infrared spectrometer by $\mathrm{KBr}$ pellet method in the range of 400 to $4000 \mathrm{~cm}^{-1}$, with a resolution of $1 \mathrm{~cm}^{-1}$. FT-IR spectrum is shown in Figure 1. The reported result is average of 20 scans. The deep absorption peak at $3398 \mathrm{~cm}^{-1}$ corresponds to $-\mathrm{OH}$ stretching vibrations. Peak at $2929 \mathrm{~cm}^{-1}$ corresponds to alkane stretching. Peaks at $1600 \mathrm{~cm}^{-1}$ and $1363 \mathrm{~cm}^{-1}$ indicate $\mathrm{C}=\mathrm{C}$ stretching and $-\mathrm{CH}_{3}$ bending vibration, respectively. As $\mathrm{MB}$ is a cationic dye, $-\mathrm{OH}$ functional groups on the surface of GNSP may increase the interaction between adsorbent and adsorbate and contribute for the adsorption of $\mathrm{MB}$.

2.3. Batch Equilibrium Studies. $100 \mathrm{~mL}$ of $\mathrm{MB}$ solution of desired concentration $(0.02,0.04,0.06,0.08,0.1,0.125,0.15$, and $0.2 \mathrm{~kg} / \mathrm{m}^{3}$ ) was taken in a $500 \mathrm{~mL}$ conical flask. $0.5 \mathrm{~g}$ of adsorbent was added to the solution, and the mixture was kept in an orbital shaker at constant temperature (303, 313, and $323 \mathrm{~K}$ ) and $200 \mathrm{RPM}$ for $24 \mathrm{~h}$ to ensure equilibrium. After $24 \mathrm{~h}$ samples were taken from each flask using a fine tip syringe to avoid carryover of solid particles. The samples were then centrifuged to collect clear supernatant solution. Concentration of $\mathrm{MB}$ was estimated using UVVis spectrophotometer, by measuring the optical density at $660 \mathrm{~nm}$. Optical density was then converted into concentration units using calibration chart [18]. Though the $\mathrm{pH}_{\mathrm{zpc}}$ of the GNSP was found to be 7.5, for adsorption studies $\mathrm{pH}$ was maintained at 7 throughout this study to minimise the addition of chemicals.

Equilibrium data was analysed with most frequently used Langmuir isotherm [26] which is given by $q_{e}=$ $q_{\max } K_{L} C_{e} /\left(1+K_{L} C_{e}\right)$. Here, $q_{e}$ is equilibrium solid-phase concentration of $\mathrm{MB}(\mathrm{kg} / \mathrm{kg}), q_{\max }$ is monolayer adsorption capacity of the adsorbent $(\mathrm{kg} / \mathrm{kg}), C_{e}$ is equilibrium liquid phase concentration of $\mathrm{MB}\left(\mathrm{kg} / \mathrm{m}^{3}\right)$, and $K_{L}$ is the Langmuir equilibrium constant $\left(\mathrm{m}^{3} / \mathrm{kg}\right)$. The Langmuir isotherm parameters $K_{L}$ and $q_{\max }$ were determined by nonlinear regression $[27,28]$ using Curve expert 1.40 (Microsoft corporation, 1993). Chi-square, defined as $\chi^{2}=\sqrt{\left(q_{e}-q_{e, m}\right)^{2} / q_{e, m}}$, was used as the error function while determining isotherm parameters by non-linear regress analysis [27]. Here, $q_{e, m}$
TABLE 1: Physical and chemical properties of GNSP used in the experiments.

\begin{tabular}{lc}
\hline Property & Value \\
\hline Moisture content $(\%)$ & 4.2 \\
Volatile matter $(\%)$ & 63.7 \\
Ash $(\%)$ & 23.8 \\
Fixed carbon $(\%)$ & 8.3 \\
Bulk density $\left(\mathrm{kg} / \mathrm{m}^{3}\right)$ & 380 \\
Average particle size, BSS \#-60+72( $\mu \mathrm{m})$ & 231 \\
$\mathrm{pH}_{\mathrm{zpc}}$ & 7.5 \\
\hline
\end{tabular}

stands for the equilibrium solid phase concentration of $\mathrm{MB}$ $(\mathrm{kg} / \mathrm{kg})$ as predicted by the model.

2.4. Column Experiments. Bulk removal of MB onto GNSP was investigated using a packed bed of BSS \#-60+72 size GNSP particles. Larger-size particles were chosen to reduce excessive pressure drop and to ensure plug flow. A $2 \mathrm{~cm}$ diameter glass column was used for this study. The column was fitted with five sampling ports located at regular intervals of $5 \mathrm{~cm}$. At the bottom of the column, $2 \mathrm{~cm}$ high layer of glass beads ( $3 \mathrm{~mm}$ dia.) was used to ensure proper distribution of inlet flow. Dye solution $\left(0.2 \mathrm{~kg} / \mathrm{m}^{3}\right)$ was introduced at the bottom of the column in upward direction at a rate of $1 \mathrm{l} / \mathrm{h}$ using a peristaltic pump. Samples were collected at regular time intervals from the sampling points located at 5, 10, and $15 \mathrm{~cm}$ heights. Performance of the column operation is described by break-through curves. Break-through time and shapes of break-through curves are very important characteristics of the column for determining the operation and dynamic response of the bed.

Volume of effluent $\left(V_{\text {eff }}\right)$ processed is calculated as:

$$
V_{\text {eff }}=Q \times t_{\text {total }}
$$

where $Q=$ volumetric flow rate in $1 / \mathrm{h}$ and $t_{\text {total }}$ is the service time of the column in h. Exhaustive time is taken as the service time $\left(t_{\text {total }}\right)$ of the column for the purpose of calculating $V_{\text {eff }}, q_{t}, m_{\text {total }}$, and $\% R$. Total amount of dye adsorbed in the column $\left(q_{t}, \mathrm{~kg}\right)$ for a given feed concentration and flow rate is calculated using the formula

$$
q_{t}=\frac{Q C_{0}}{1000} \int_{t=0}^{t=t_{\text {total }}}\left(1-\frac{C_{t}}{C_{0}}\right) d t
$$

where $C_{0}$ is initial concentration in $\mathrm{kg} / \mathrm{m}^{3}$ and $t$ is time in $\mathrm{h}$. If the total amount of dye passed through the column is $m_{\text {total }}$ $\left(=Q C_{0} t_{\text {total }} / 1000\right)$, then percentage dye removed is calculated as

$$
\text { Total percentage removal, } \% R=\frac{q_{t}}{m_{\text {total }}} \times 100
$$

2.5. Bed Depth Service Time (BDST) Model. Bed depth service time model [29] is a simple model that assumes a linear relationship between bed height and service time of a column. 


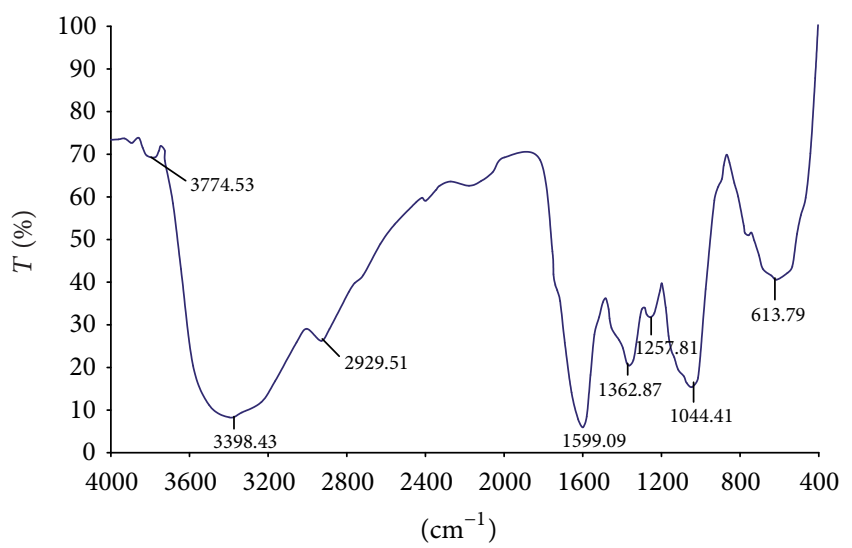

FIGURE 1: FTIR of groundnut shell powder.

The equation can be expressed as:

$$
t_{b}=\frac{N_{0} Z_{0}}{C_{0} U_{0}}+\frac{1}{K_{a} C_{0}} \ln \left(\frac{C_{0}}{C_{B}}-1\right),
$$

where $t_{b}, N_{0}, Z_{0}, C_{0}, U_{0}, K_{a}$, and $C_{b}$ are break-through time (h), bed capacity $\left(\mathrm{kg} / \mathrm{m}^{3}\right)$, bed height $(\mathrm{m})$, initial dye concentration $\left(\mathrm{kg} / \mathrm{m}^{3}\right)$, superficial velocity through bed $(\mathrm{m} / \mathrm{h})$, kinetic constant $\left(\mathrm{m}^{3} / \mathrm{kg} \mathrm{h}\right)$, and break-through concentration $\left(\mathrm{kg} / \mathrm{m}^{3}\right)$, respectively. In spite of ignoring the intra-particle mass transfer resistance and external film resistance, the model fits many packed bed adsorption systems well and provides information $\left(N_{0}\right.$ and $\left.K_{a}\right)$ useful for scale up of given adsorption system [24].

2.6. The Thomas Model. Prediction of concentration-time profile and maximum adsorption capacity is important for satisfactory design of a column adsorption. The Thomas model $[18,24]$ is one of the most general and widely used models to describe packed bed adsorption. It assumes (i) Langmuir's isotherm, (ii) no axial dispersion, and (iii) second-order adsorption kinetics. Linear form of the model is given by the equation $[29,30]$ :

$$
\ln \left(\frac{C_{0}}{C}-1\right)=\frac{K_{\mathrm{Th}} q_{0} X}{Q}-\frac{K_{\mathrm{Th}} C_{0}}{Q} V_{\mathrm{eff}}
$$

The kinetic parameters $K_{\mathrm{Th}}\left(\mathrm{m}^{3} \mathrm{~kg}^{-1} \mathrm{~h}^{-1}\right)$ and $q_{0}(\mathrm{~kg} / \mathrm{kg})$ were determined from the slope and intercept of the plot of $\ln \left(C_{0} / C_{b}-1\right)$ versus $t$ at a given flow rate.

\section{Results and Discussion}

3.1. Batch Equilibrium Studies. Equilibrium curves are shown in Figure 2. Langmuir's isotherm parameters determined by non-linear regression are given in Table 2. High $R^{2}$ values $(\approx 1)$ indicate the goodness of fit. The values of Langmuir's monolayer adsorption capacities, shown in Table 2 , indicate the efficiency of GNSP as an alternate adsorbent.



$$
\begin{aligned}
& \text { - 303, exp } \\
& \triangle 313, \exp \\
& \triangle 323, \exp
\end{aligned}
$$

FIgURE 2: Equilibrium studies on adsorption of MB onto GNSP. $\left(\mathrm{RPM}=200, T=303,313\right.$, and $323 \mathrm{~K}$, adsorbent $=0.5 \mathrm{~kg} / \mathrm{m}^{3}, \mathrm{pH}$ $=7)$.

TABLE 2: Langmuir's isotherm parameters for the adsorption of MB onto GNSP.

\begin{tabular}{lccc}
\hline Parameter & $303 \mathrm{~K}$ & $313 \mathrm{~K}$ & $323 \mathrm{~K}$ \\
\hline$K_{L}\left(\mathrm{~m}^{3} / \mathrm{kg}\right)$ & 78.23 & 93.16 & 126.13 \\
$q_{m}(\mathrm{~kg} / \mathrm{kg})$ & 0.242 & 0.188 & 0.127 \\
$R^{2}$ & 0.989 & 0.990 & 0.978 \\
$\chi^{2}$ & 0.63 & 0.37 & 0.08 \\
\hline
\end{tabular}

\subsection{Column Studies}

3.2.1. Bed-Depth Service Time (BDST). Effect of bed depth was studied at a constant initial dye concentration of $0.2 \mathrm{~kg} / \mathrm{m}^{3}$. Samples were drawn from various heights of the column. Figure 3 shows the break-through curve for the adsorption of MB using a fixed bed of GNSP. Break-through concentration was fixed as $10 \%$ of initial concentration (that is $\left.0.02 \mathrm{~kg} / \mathrm{m}^{3}\right)$. Break-through time increased with increase in bed height in consistent with the theory. Values of $N_{0}$ and $K_{a}$ are found to be $77.99 \mathrm{~kg} / \mathrm{m}^{3}$ and $0.45 \mathrm{~m}^{3} \mathrm{~kg}^{-1} \mathrm{~h}^{-1}$, respectively. Percentage color removal was calculated be 67 , 77 , and 79 , respectively, for bed heights 5,10 , and $15 \mathrm{~cm}$. Percentage color removal increases with increase in bed height as utilisation of bed improves with increase in bed height [24].

3.2.2. The Thomas Model. The Thomas model plot is shown in Figure 4. The model parameters $K_{\mathrm{Th}}$ and $q_{0}$ are presented in Table 3. High $R^{2}$ values obtained indicate that Thomas model fits the experimental data well for this system. Comparison of experimental and predicted break-through curves is shown in Figure 3. The values of $K_{\text {Th }}$ decreased with increase in bed height. Values of $q_{0}$ predicted by the Thomas model were in the range of $0.272,0.238$, and $0.241 \mathrm{~kg} / \mathrm{kg}$. These 


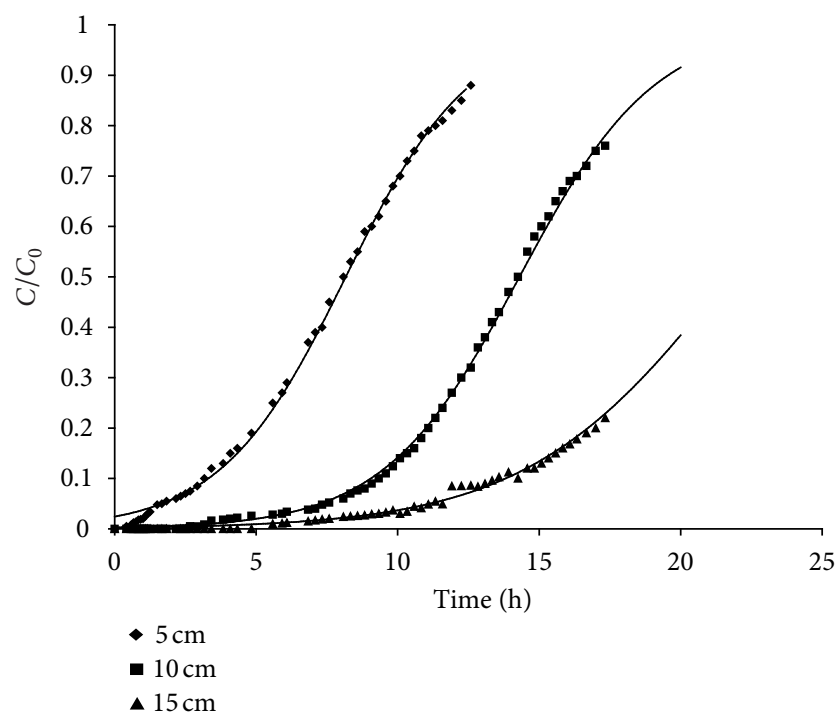

FIGURE 3: Break-through curves for MB adsorption onto GNSP at different bed heights. Flow rate $=1 \mathrm{l} / \mathrm{h}$, initial dye concentration $=$ $0.2 \mathrm{~kg} / \mathrm{m}^{3}, \mathrm{pH}=7$.

TABLE 3: The Thomas model parameters.

\begin{tabular}{lccc}
\hline Bed height $(\mathrm{cm})$ & $q_{0}(\mathrm{~kg} / \mathrm{kg})$ & $K_{\mathrm{TH}}\left(\mathrm{m}^{3} / \mathrm{kgh}\right)$ & $R^{2}$ \\
\hline 5 & 0.272 & 2.262 & 0.99 \\
10 & 0.238 & 2.091 & 0.99 \\
15 & 0.241 & 1.395 & 0.99 \\
\hline
\end{tabular}

are comparable with the actual values $0.253,0.228$, and $0.231 \mathrm{~kg} / \mathrm{kg}$ as calculated using (2). This shows that the prediction of the Thomas model is close enough to the actual values. The difference seen here is largely due to the deviation of the Thomas model during the initial period. It is seen that the height of the bed did not show any definite effect on $q_{0}$. This suggests plug flow conditions prevailed in the column and the axial dispersion was negligible. This is comparable to other low-cost adsorbents reported in the literature [24]. This indicates that the GNSP has good adsorption potential and it can be employed as an alternate adsorbent.

\section{Conclusion}

Continuous removal of methylene blue from aqueous solution was studied using a fixed bed packed with of groundnut shell powder. Up to $80 \%$ color removal was possible with the fixed bed. Thomas model could satisfactorily predict the adsorption break-through curve. Adsorption capacity of the bed was found to be in the range of 0.238 to $0.272 \mathrm{~kg} / \mathrm{kg}$. These results demonstrate that groundnut shell powder possesses good adsorption capacity and can be effectively used as a low cost alternate adsorbent for the removal of pollutants like methylene blue from industrial effluents.

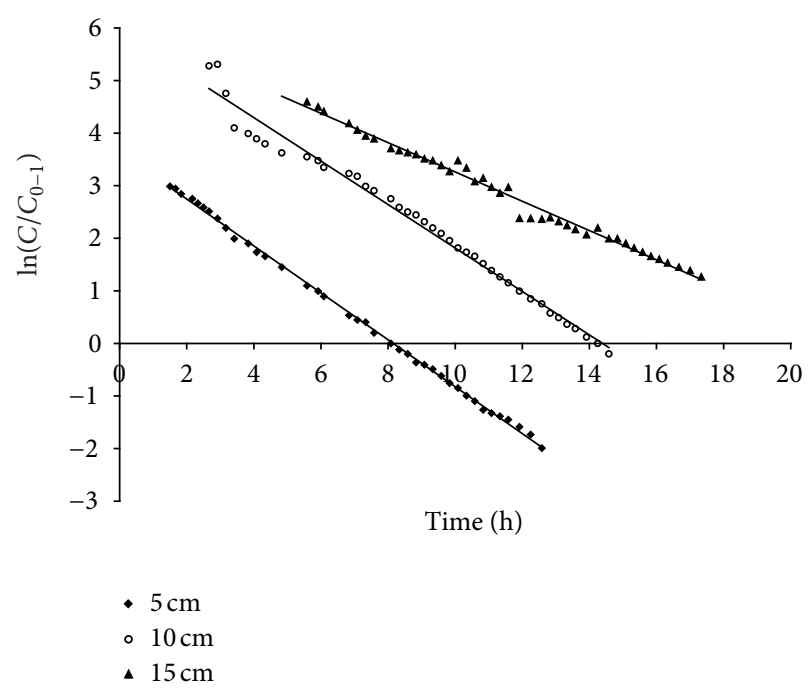

Figure 4: The Thomas model curve for MB adsorption onto GNSP at different bed heights. Flow rate $=11 / \mathrm{h}$, initial dye concentration $=0.2 \mathrm{~kg} / \mathrm{m}^{3}, \mathrm{pH}=7$.

\section{Acknowledgment}

All authors sincerely thank the SASTRA management for the facilities provided to carry out the research project and like to acknowledge their help.

\section{References}

[1] M. S. Chiou and H. Y. Li, "Equilibrium and kinetic modeling of adsorption of reactive dye on cross-linked chitosan beads," Journal of Hazardous Materials, vol. 93, no. 2, pp. 233-248, 2002.

[2] V. Ponnusami, K. S. Rajan, and S. N. Srivastava, "Application of film-pore diffusion model for methylene blue adsorption onto plant leaf powders," Chemical Engineering Journal, vol. 163, no. 3, pp. 236-242, 2010.

[3] T. Robinson, B. Chandran, and P. Nigam, "Removal of dyes from a synthetic textile dye effluent by biosorption on apple pomace and wheat straw," Water Research, vol. 36, no. 11, pp. 2824-2830, 2002.

[4] D. Özer, G. Dursun, and A. Özer, "Methylene blue adsorption from aqueous solution by dehydrated peanut hull," Journal of Hazardous Materials, vol. 144, no. 1-2, pp. 171-179, 2007.

[5] A. Khaled, A. El Nemr, A. El-Sikaily, and O. Abdelwahab, "Treatment of artificial textile dye effluent containing direct yellow 12 by orange peel carbon," Desalination, vol. 238, no. 1-3, pp. 210-232, 2009.

[6] Y. Yang, X. Wei, P. Sun, and J. Wan, "Preparation, characterization and adsorption performance of a novel anionic starch microsphere," Molecules, vol. 15, no. 4, pp. 2872-2885, 2010.

[7] M. Ahmaruzzaman and V. K. Gupta, "Rice husk and its ash as low-cost adsorbents in water and wastewater treatment," Industrial and Engineering Chemistry Research, vol. 50, no. 24, pp. 13589-13613, 2011.

[8] Y. Safa and H. N. Bhatti, "Biosorption of direct red-31 and direct orange-26 dyes by rice husk: application of factorial design analysis," Chemical Engineering Research and Design, vol. 89, no. 12, pp. 2566-2574, 2011. 
[9] V. Ponnusami, N. Lavanya, M. Meenal, R. A. G. Raj, and S. N. Srivastava, "Application of nitric acid treated rice husk for sorption of reactive dye reactive black 5: analysis using statistical experimental design," Pollution Research, vol. 27, no. 1, pp. 45-48, 2008.

[10] M. Mirjalili, M. B. Tabatabai, and L. Karimi, "Novel herbal adsorbent based on wheat husk for reactive dye removal from aqueous solutions," African Journal of Biotechnology, vol. 10, no. 65, pp. 14478-14484, 2011.

[11] V. K. Verma and A. K. Mishra, "Removal of dyes using low cost adsorbents," Indian Journal of Chemical Technology, vol. 15, pp. 140-145, 2008.

[12] H. B. Ahmad, M. Aleem, T. Anwar, M. N. Ashiq, and M. Yousaf, "Comparative studies for the adsorption of remazol blue on rice husk, saw dust and charcoal," Journal of the Chemical Society of Pakistan, vol. 33, no. 4, pp. 449-453, 2011.

[13] K. Vasanth Kumar and K. Porkodi, "Equilibrium and thermodynamics of dye removal from aqueous solution by adsorption using rubber wood saw dust," International Journal of Environmental Technology and Management, vol. 10, no. 3-4, pp. 295-307, 2009.

[14] H. Pekkuz, I. Uzun, and F. Güzel, "Kinetics and thermodynamics of the adsorption of some dyestuffs from aqueous solution by poplar sawdust," Bioresource Technology, vol. 99, no. 6, pp. 2009-2017, 2008.

[15] S. T. Ong, P. S. Keng, M. S. Voon, and S. L. Lee, "Application of durian peel (Durio zibethinus Murray) for removal of methylene blue from aqueous solution," Asian Journal of Chemistry, vol. 23, no. 7, pp. 2898-2902, 2011.

[16] V. Dharmalingam, A. K. Ramasamy, and V. Balasuramanian, "Chemical modification on reactive dye adsorption capacity of castor seeds," E-Journal of Chemistry, vol. 8, supplement 1, pp. S335-S343, 2011.

[17] E. I. Unuabonah, G. U. Adie, L. O. Onah, and O. G. Adeyemi, "Multistage optimization of the adsorption of methylene blue dye onto defatted Carica papaya seeds," Chemical Engineering Journal, vol. 155, no. 3, pp. 567-579, 2009.

[18] V. Ponnusami, V. Gunasekar, and S. N. Srivastava, "Kinetics of methylene blue removal from aqueous solution using gulmohar (Delonix regia) plant leaf powder: multivariate regression analysis," Journal of Hazardous Materials, vol. 169, no. 1-3, pp. 119-127, 2009.

[19] V. Ponnusami, R. Madhuram, V. Krithika, and S. N. Srivastava, "Effects of process variables on kinetics of methylene blue sorption onto untreated guava (Psidium guajava) leaf powder: statistical analysis," Chemical Engineering Journal, vol. 140, no. 1-3, pp. 609-613, 2008.

[20] V. Ponnusami and S. N. Srivastava, "Studies on application of teak leaf powders for the removal of color from synthetic and industrial effluents," Journal of Hazardous Materials, vol. 169, no. 1-3, pp. 1159-1162, 2009.

[21] T. Murugan, A. Ganapathi, and R. Valliappan, "Removal of dyes from aqueous solution by adsorption on biomass of mango (Mangifera indica) leaves," E-Journal of Chemistry, vol. 7, no. 3, pp. 669-676, 2010.

[22] T. Murugan, A. Ganapathi, and R. Valliappan, "Removal of grey BL from dye wastewater by derris (Pongamia glabra) leaf powder by adsorption," E-Journal of Chemistry, vol. 7, no. 4, pp. 1454-1462, 2010.

[23] K. G. Bhattacharyya and A. Sharma, "Kinetics and thermodynamics of methylene blue adsorption on neem (Azadirachta indica) leaf powder," Dyes and Pigments, vol. 65, no. 1, pp. 51-59, 2005.

[24] V. Ponnusami, S. Vikram, and S. N. Srivastava, "Guava (Psidium guajava) leaf powder: novel adsorbent for removal of methylene blue from aqueous solutions," Journal of Hazardous Materials, vol. 152, no. 1, pp. 276-286, 2008.

[25] K. V. Kumar and K. Porkodi, "Mass transfer, kinetics and equilibrium studies for the biosorption of methylene blue using Paspalum notatum," Journal of Hazardous Materials, vol. 146, no. 1-2, pp. 214-226, 2007.

[26] I. Langmuir, "The constitution and fundamental properties of solids and liquids. Part I. Solids," Journal of the American Chemical Society, vol. 38, no. 11, pp. 2221-2295, 1916.

[27] Y. S. Ho, "Selection of optimum sorption isotherm," Carbon, vol. 42, no. 10, pp. 2115-2116, 2004.

[28] Y. S. Ho, C. C. Chiang, and Y. C. Hsu, "Sorption kinetics for dye removal from aqueous solution using activated clay," Journal of Separation Science and Technology, vol. 36, no. 11, pp. 2473-2488, 2001.

[29] T. V. N. Padmesh, K. Vijayaraghavan, G. Sekaran, and M. Velan, "Biosorption of Acid Blue 15 using fresh water macroalga Azolla filiculoides: batch and column studies," Dyes and Pigments, vol. 71, no. 2, pp. 77-82, 2006.

[30] Z. Aksu and F. Gonen, "Biosorption of phenol by immobilized activated sludge in a continuous packed bed: prediction of breakthrough curves," Process Biochemistry, vol. 39, no. 5, pp. 599-613, 2004. 

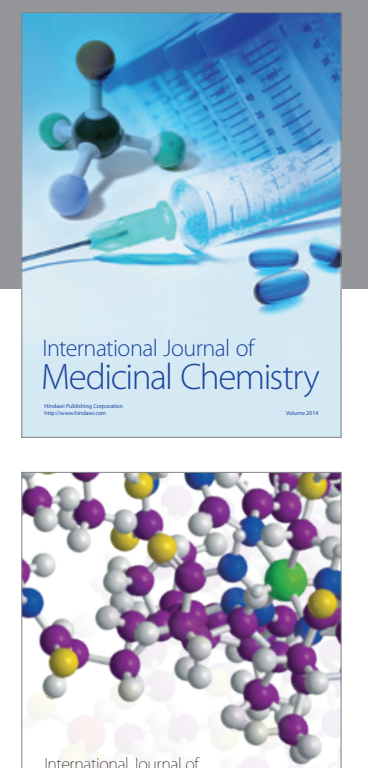

\section{Carbohydrate} Chemistry

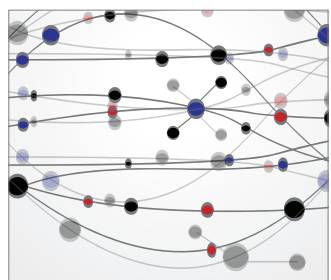

The Scientific World Journal
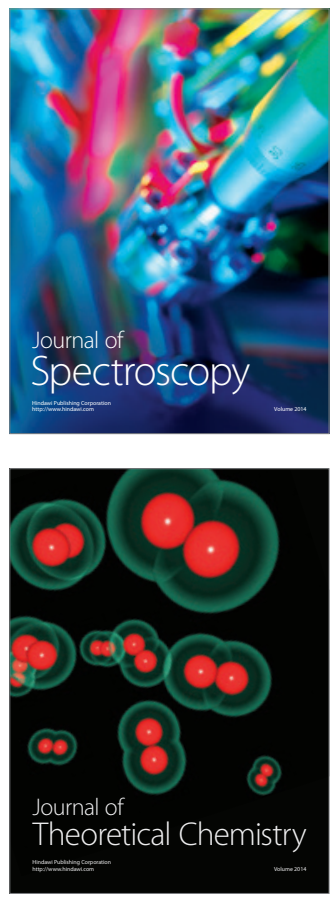
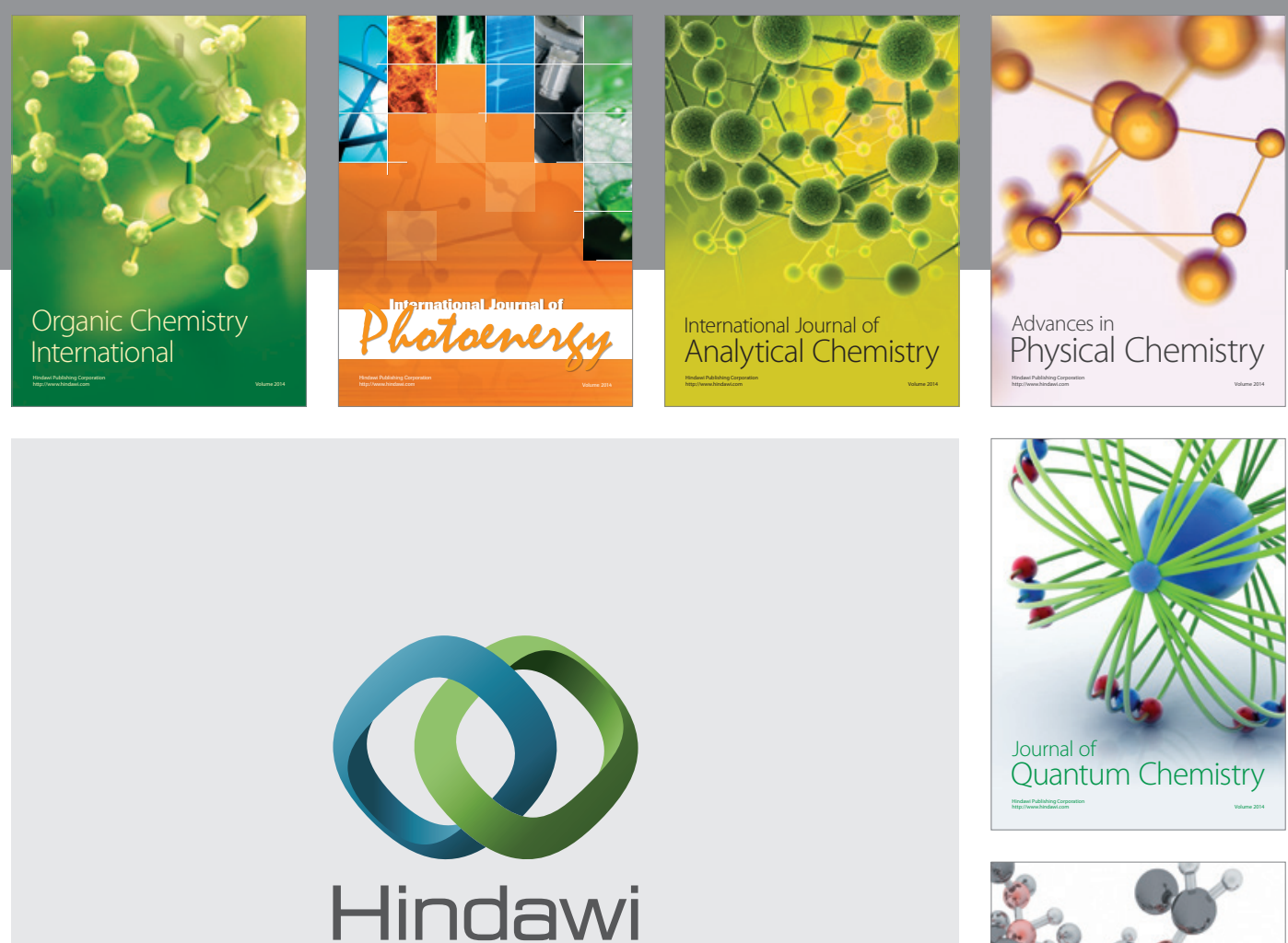

Submit your manuscripts at

http://www.hindawi.com

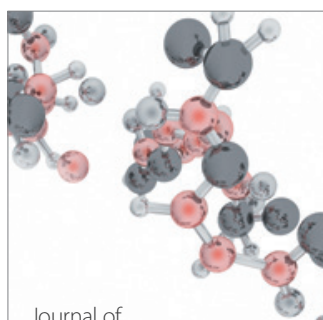

Analytical Methods

in Chemistry

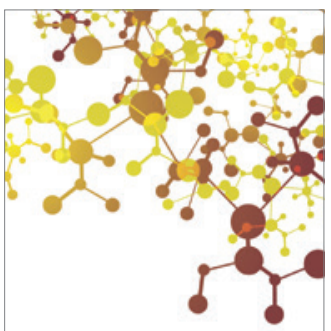

Journal of

Applied Chemistry

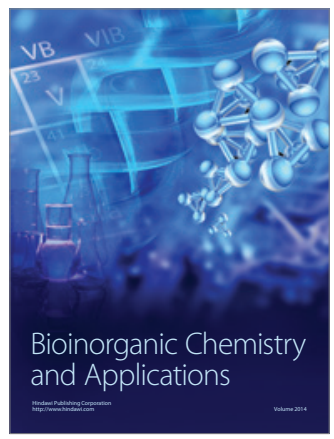

Inorganic Chemistry
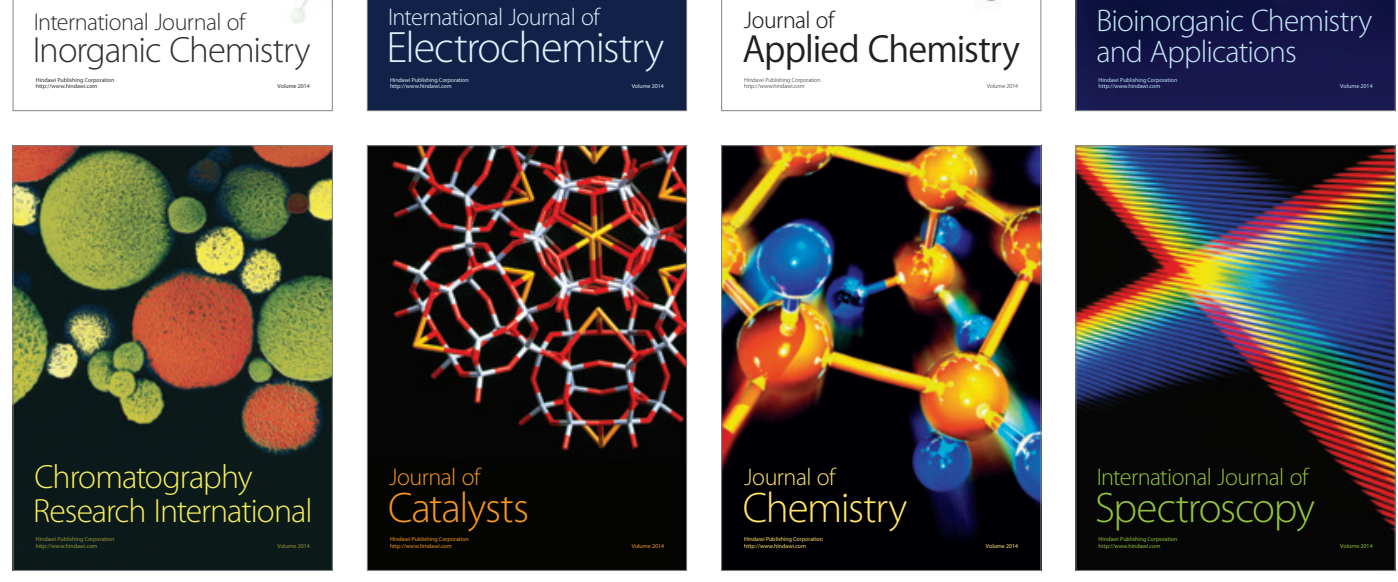